\title{
Epísteme de la economía: una aproximación desde la economía social ${ }^{\star}$
}

\section{Episteme of the economy: an approximation from the social economy}

\author{
Carlos Julio Martínez Becerra**
}

\section{Resumen}

La actual crisis de la economía afecta de manera especial a los países del primer mundo, genera inquietudes en todos los sectores y con mayor énfasis en aquellos responsables de la formación científica en economía. Hace poco tiempo un grupo de estudiantes de la cátedra Introducción a la Economía de la Universidad de Harvard se resistió a recibir clase del famoso economista Gregory Mankiw, exasesor del presidente George W. Bush y autor de uno de los manuales de macroeconomía utilizado en las mejores escuelas dentro y fuera de Estados Unidos, por considerar que los conocimientos impartidos no coadyuvan a la solución de los problemas económicos que afronta la humanidad. La fundamentación epistemológica de la economía social implica construir un escenario académico en el que la teoría económica sirve como soporte para abordar los problemas de la sociedad desde diversas líneas conceptuales, en particular, el realismo, el idealismo deductivista empírico y el inductivo con énfasis en el humanismo, principio orientador de la economía al servicio del hombre.

Palabras clave: economía social, solidaridad, distribución, verdad, justicia, seguridad humana.

Clasificación JEL: A11, B25, F36, I31

* El presente documento forma parte del trabajo de investigación que adelanta la Facultad de Economía, en ejecución del Convenio No 020 2011, suscrito con DANSOCIAL (actual Unidad Administrativa Especial de Organizaciones Solidarias, adscrita al Ministerio de Trabajo).

** Economista de la Universidad Nacional de Colombia; doctor en Economía de la Universidad de París, con estudios posdoctorales en Geopolítica de Estados Unidos y en Economía Marítima; decano de la Facultad de Economía de la Universidad Santo Tomás. correo electrónico: cmartinbe@gmail.com 


\section{Abstract}

The current economic crisis affects in particular first world countries, it raises concerns in all sectors and with greater emphasis on those responsible for science education in economics. Recently a group of students of the Introduction to Economics class at Harvard University refused to be lectured by famous economist Gregory Mankiw, former advisor for Bush's administration and author of one of the major textbooks in macroeconomics used in the best schools within and outside the United

\section{Introducción}

Si el mercado se rige únicamente por el principio de la equivalencia del valor de los bienes que se intercambian, no llega a producir la cohesión social que necesita para su buen funcionamiento. Sin formas internas de solidaridad y de confianza recíproca, el mercado no puede cumplir plenamente su propia función económica. Hoy, precisamente esta confianza ha fallado y esta pérdida de confianza es algo realmente grave (Pablo VI).

La tarea de abordar los problemas socioeconómicos, con el propósito de sugerir soluciones sostenibles, implica apelar a las categorías de la ciencia económica para conducir las vías de desarrollo económico al ámbito de lo concreto. En este sentido, el análisis del crecimiento económico es fundamental como indicador de la generación de riqueza, pero también como fuente para su distribución con el objetivo de procurar el bienestar y el bienvivir de la sociedad. Un sustrato social de la distribución humanista está asociado con el concepto de compartir como orientador de la dinámica social.
States. These students considered in fact that the given knowledge does not contribute to solving the economic problems faced by humankind. The epistemological basis of social economy means building an academic setting in which economic theory serves as a support to address the problems of society from different conceptual lines, including realism, deductive empirical idealism and the inductive one with emphasis on humanism, guiding principle of economy at the service of man.

Keywords: social economy, solidarity, sharing, truth, justice, human security.

Ante la crisis de valores derivada de la conducta mercantilista de los agentes económicos, esta se ha convertido en una fuente de reflexión entre los economistas de todos los continentes. Para este abordaje, la economía apela al análisis de hechos y valores. La acción económica, como paso previo al desarrollo, exige que la economía sea un escenario de análisis crítico y de compromiso con la sociedad, en los ámbitos local, regional, nacional e internacional. En este proceso de reflexión teórica y de propuestas políticas, el hecho fundamental en economía debe ser la verdad. Por esta razón, un hecho es, en términos epistemológicos, una observación objetiva y verificable (Mourão, 2007).

En los albores de la economía moderna, David Hume examinó la línea tenue entre "hechos y valores". Sin embargo, a finales del siglo XX, la posición de la ciencia económica frente a la dinámica de los hechos comparada con los valores ha producido cuatro corrientes: realismo, no cognitivismo, relativismo y escepticismo, controversia que se remonta a las escuelas griegas clásicas (SayreMcCord, 1988; Brink, 1989; Japiassu, 2000; Mourão, 
2007, p. 385). Tomás de Aquino, por su parte, insistió en el bien común y fundamentó su argumento en "los juicios naturales que rigen los seres". Sin embargo, muchos analistas han considerado que las causas y los hechos son independientes de las entidades que toman decisiones ${ }^{1}$. Por ejemplo, hoy podría afirmarse que el concepto de mercado es un eufemismo para ocultar intereses particulares. Para comprender esta afirmación bastaría asignar nombres a los eventuales afectados por un comportamiento específico de la economía. Coloquialmente se habla de los precios del mercado, cuando en realidad asistimos a un escenario competido en el que existe un orden económico mundial regido siempre por los poderosos, legítimos e ilegítimos.

Algunos economistas, entre los que se podría mencionar a Malthus y a Ricardo, fueron más cercanos a la visión escéptica de la realidad. Incluso se afirma que apelar a los valores para explicar el comportamiento de la economía es entrar en el ámbito de no generación de conocimiento. Es decir, con los valores no se puede ni crear ni transmitir conocimiento. Sin embargo, por no atender esta necesaria simbiosis, que en términos actuales podría asimilarse a la ética científica, los creadores de la bomba atómica estuvieron divorciados de la destinación dada por los "usuarios" a ese producto, que, aplicado para resolver las relaciones de poder en el ámbito internacional, condujo al holocausto en Hiroshima y Nagasaki (Mourão, 2007,

1 El bien común no es solo un conjunto de ventajas y utilidades, sino rectitud de vida, algo éticamente bueno. Lo que constituye el bien común de la sociedad política no es solamente el conjunto de bienes y servicios de utilidad pública o de interés nacional (caminos, puertos, escuelas, etc.), ni las buenas finanzas del Estado, ni su pujanza militar. No es solamente el conjunto de leyes justas, de buenas costumbres y de instituciones sabias que dan su estructura a la nación, ni la herencia de los gloriosos recuerdos históricos, de sus símbolos y de sus glorias, de sus tradiciones y de sus tesoros de cultura. El bien común comprende sin duda todas esas cosas, pero con más razón otras muchas: algo más profundo, más concreto y más humano. p. 338). Antes del lanzamiento de la bomba sobre el territorio japonés más promisorio en términos industriales se había producido el acto de guerra facilitado por Estados Unidos en Pearl Harbor.

Otro aspecto asociado con esta controversia es el relacionado con "el ser y el deber ser". Weber, por ejemplo, advirtió que en la ciencia no había espacio para valores o juicios de valor. Toda ciencia se basa en conocimiento empírico, mientras que el valor se basa en sentimientos individuales. Es claro que la consideración de hechos y valores establece y debe establecer un espacio de pluralidad y de contradicción creativa. Los valores, como articulación entre hechos y agentes, constituyen una fuente de reflexión importante en términos metodológicos como objeto de estudio de la economía. Sin embargo, en economía, el manejo comparado entre hechos y valores no puede dividirse como puede ocurrir en algunas ciencias, entre otras razones porque la experimentación puede tener efectos sociales irreversibles. Esta afirmación es muy significativa en nuestra época por cuanto los economistas que conforman los denominados bancos de pensamiento pueden hacer aparecer como científico lo que solo es una tarea asignada por los mecenas que financian sus investigaciones. Incluso pueden inducir a la duda sobre la información debido a su dependencia del denominado mecenazgo. Hablaríamos de científicos a destajo que legitiman con sus teorías las acciones de los agentes económicos legítimos e ilegítimos, pues, entre los nuevos agentes, la geopolítica posmoderna trajo las denominadas industrias criminales.

Pinto (2000), un lúcido reflexivo, advierte que "quienes no se interesen en la economía tienen el castigo de ser gobernados por quienes se interesan en ella", con el efecto colateral de conducir esta ciencia por el sendero que sirva a sus intereses individuales, sin considerar el bien común como el fin último de la economía al servicio del hombre. La humanidad es una aspiración, algo que se alcanza en 
el ejercicio de la plena razón; los usos de la razón han demostrado que esta no siempre es suficiente para un tiempo mejor. Ser racional en términos de moralidad y eticidad es encauzar la racionalidad desde un ethos doble que contenga nuestra morada interior, metáfora de la conciencia moral y que incluya al grupo social de pertenencia.

Popper también ha contribuido al debate sobre los hechos y los valores en economía, reiterando la necesidad de defender el cientifismo en economía con el ánimo de rescatar su carácter neutral, incluso con la advertencia de que las teorías solo son científicas si son falseables. Monetaristas de la denominada escuela de Chicago, bajo el liderazgo de Milton Friedman, contribuyeron con éxito regional a la construcción de modelos "estilizados" centrados en el crecimiento económico, sin tomar en cuenta la distribución como una de sus variables activas, ni la justicia social derivada.

En este ámbito, podría afirmarse que la tecnocracia es neutral, es científica, pero oculta la real condición del tecnócrata que es un ideólogo funcional, si no se somete a la crítica, ni a la revisión de los hallazgos que pueda obtener en el desempeño de sus funciones laborales. Ante esta realidad, Mourãu (2007) advierte que no pueden existir feudos donde los campos científicos se resguarden de la crítica y de la discusión. Al contrario, el verdadero economista empieza por el conocimiento de las causas últimas (Blaug, 1992, p. 119), apelando al método científico. Esta controversia ha contribuido a la emergencia del análisis económico comparativo entre el método estático comparativo y la dinámica económica.

Frente a estas versiones de pragmatismo económico de finales del siglo XX y comienzos del XXI, varios autores han considerado que la vitalidad de una ciencia reside en que "solo se elige lo que se valora". Con el advenimiento de la crisis de la economía de los Estados Unidos extendida por Europa y el resto del mundo entre 2007 y 2008, la controversia no termina, se modifica creativamente. Aparece en el escenario la valoración entre la efectividad de la economía de mercado, la economía pública y la economía social como opciones para la determinación de los problemas de esta ciencia y las formas cada vez más diversas para afrontar dicha crisis.

Podría afirmarse que después de las propuestas de los clásicos, en la denominada economía moderna, la controversia fue el lugar común del pensamiento económico. Incluso hay economistas que afirman que la teoría económica que surgió de la Guerra Fría, en nuestros tiempos corresponde al alineamiento ideológico como inspirador de los teóricos de mediados del siglo XX, articulados con la controversia derivada de la nueva geopolítica construida después de la terminación de la Segunda Guerra Mundial y asociada al realismo político como orientador de las relaciones de poder a nivel mundial. En estas circunstancias históricas, la política exterior se erige como la nueva geopolítica, en particular a partir de la caída del socialismo real. La aparente hegemonía del mercado como única vía para el crecimiento y el desarrollo económico, considerada por algunos autores como el fin de la historia (Fukuyama, 1992), ha comenzado a generar dudas sobre su validez con los resultados de las medidas de austeridad como camino a la salida de la crisis en Europa y Estados Unidos.

Así las cosas, nosotros podríamos invocar la economía social como parte de la solución a la crisis estructural de la economía mundial. En efecto, según Cárdenas y Cháves (2011)

...la economía social como corriente de pensamiento es un conjunto de iniciativas teóricas, epistemológicas y organizacionales propias de la economía, regidas por la ética humana cuya complejidad es solo entendible desde un punto de vista interdisciplinar. El buen vivir, los 
ecosistemas industriales, los casos exitosos de la economía solidaria (también llamada tercer sector), las teorías alternativas de desarrollo, entre muchas otras manifestaciones de la economía social que en este mundo homogenizado son empañadas e ignoradas, tienen una intención humanitaria que revalúa el pensamiento tradicional económico y defiende la equidad, la sostenibilidad y el bien común.

\section{La deontología en economía}

El ser y el deber ser en economía se asocian con la economía positiva y con la economía normativa, respectivamente $^{2}$. La primera, relatora, intérprete y planificadora de hechos, en la que el poder de facto domina al poder político. La segunda, basada en valores, procura darle sentido al poder político ilustrado para regular el poder de facto como mecanismo de facilitación de la democratización en el acceso al bienestar general de la población, y también apela a indicadores relevantes de profundas raíces científicas (Sen, 1980). Obrar conforme a la razón es atreverse a la conciencia histórica, es decir, abrirse a la comprensión del mundo en el que vivimos, mundo que heredamos y que nos marca, pero no nos determina, al punto de no poder transformarlo. De igual forma, significa la posibilidad de fijarnos nuestras propias leyes, no como individuos, sino como sujetos sociales.

En consecuencia, podría afirmarse que la economía es un espacio de pluralidad y de contradicción creativa, que en

2 La deontología se conoce como el conjunto ordenado de deberes y obligaciones morales que tienen los profesionales de una determinada materia. Trata los "códigos de conducta" de las profesiones y, actualmente, se estudia como una rama de la ética, es decir, la ética que indaga los deberes de los profesionales. Proviene de los vocablos griegos deon, deber y logos, razonamiento o ciencia. El término fue empleado por primera vez por el economista, jurista, literato y filósofo inglés Jeremías Bentham (1748-1832), quien en su libro Deontology or the Science of Morality desarrolló una doctrina acerca de los distintos deberes, concebidos sobre una base utilitarista aplicada a determinadas situaciones sociales. el siglo XX se expresó en la experiencia comparada de la Unión Soviética y Estados Unidos como líderes de dos sistemas controversiales incapaces de resolver muchos interrogantes relacionados con la justicia social en la economía. De las economías centralizadas se critica la ausencia de iniciativas privadas e individuales y la carencia de una relación activa entre industria militar e industria civil para hacer más productiva su economía; del capitalismo y el libre mercado se objeta que no han sido capaces de resolver problemas como la pobreza y la desigualdad pero, en cambio, han permitido la acumulación que incorpora actividades ilegítimas y criminales por parte de empresas que por su poder económico se han convertido en verdaderos supraEstados. Esa es la nueva geopolítica que se filtra entre las fronteras y que con el pretexto de la globalización ensancha los mercados mediante procesos de aculturación que violentan la voluntad general, convirtiendo a los ciudadanos en simples consumidores del sistema económico internacional.

Para el liberalismo económico clásico y para el denominado neoliberalismo de hoy, la única justicia es la decretada por el mercado. Incluso, autores de la ciencia política advierten que el mercado puede asumir visos de dictadura en contraposición a la democracia que se supone implícita en el ámbito de las libertades asociadas al mercado. En este caso se advierte que la racionalidad no es compatible con la justicia, a pesar de las serias reflexiones de Amartya Sen en sentido contrario. Otras reflexiones de carácter fatalista sugieren que es el destino, la lotería de la vida, la que reserva a cada uno su condición social.

\section{La distribución y la solidaridad}

Para autores como Rawls (1971), la imparcialidad y equidad de los principios de justicia serán mejor custodiadas 
si los contratantes ignoran su situación de clase. Primero es la libertad, luego es la justicia. La distribución ha de referirse a bienes primarios, como riqueza, poder, derechos políticos, distinguiéndolos de los que son producto de la naturaleza, como la inteligencia, la salud o la fortaleza física (Boron, 2000a). Por su parte, Hayek (1978) rechaza por completo siquiera la posibilidad de pensar en la justicia social. Rawls, con gran influencia kantiana presenta al menos la inquietud sobre la justicia como escape al darwinismo social de mercado de finales del siglo $\mathrm{XX}$. Considera que la justicia es la primera virtud de las instituciones sociales, como la verdad lo es de los sistemas de pensamiento (Boron, 2000a). Para Rawls, la justicia se construye sobre la base de la democracia de la propiedad privada. El problema es que si los propietarios retienen un control irrestricto de las decisiones de inversión, deciden si invierten o no, dónde y cuándo, si especulan o no, con lo cual pueden resultar afectadas amplias capas de la sociedad (Boron, 2000a; Cohen, 1991; Przeworski, 1989). La decisión de invertir, asociada con la confianza inversionista puede poner en riesgo a potenciales empresarios y trabajadores, lo que puede traducirse en un totalitarismo de los inversionistas. Estos normalmente reivindican confianza y seguridad jurídica para su ejercicio libre, asociado a grandes costos fiscales por estímulos tributarios a los que en buena parte de las actividades es necesario agregar la elusión y la evasión fiscal. El solidarismo filosófico de Rawls podría ser una forma de mantener el statu quo al no reconocer las condiciones de explotación existentes en el actual manejo de la economía, como tampoco la importancia fiscal de actividades ilegales de las grandes empresas, en particular asociadas con la corrupción que, en ocasiones, ha significado la compra de gobiernos locales o regionales para hacer viables sus proyectos inversionistas. Para Hayek, la justicia social es espuria en su totalidad (Boron, 2000a). Este filósofo, jurista y economista insiste en la innovación porque permite desafiar las normas grupales y hacer pensar por sí mismos y en sí mismos, es decir, en el reino del individualismo. En este caso, el capitalismo aparece como el "remate natural" de la evolución del espíritu humano y su talante irremisiblemente adquisitivo y egoísta (Boron, 2000a, p. 144). Hayek es conocido como el más dogmático defensor de la economía de mercado, contrario al pensamiento humanista de Santo Tomás.

Tomás de Aquino, en la Suma Teológica - cinco siglos antes de la publicación de La riqueza de las naciones de Adam Smith-, y Louis Joseph Lebret -en el siglo XX, con su contribución a la Doctrina Social de la Iglesia, planteada en la encíclica Populorum Progressio-, consideran que la justicia es factor de verdad y de caridad, cuando se propone el bien común como un orientador apropiado de lo que hoy se conoce como el bien estar y el bien vivir de la sociedad. Esta encíclica asignó un papel central a los poderes públicos. En 2009, en la encíclica Caritas in Veritate $^{3}$, el Papa Benedicto XVI reivindicó la justicia y la verdad como elementos necesarios para el desarrollo humano y afirmó que la libertad sin verdad es insuficiente y puede falsear los elementos más profundos de aquella ${ }^{4}$. Más que intervenciones de carácter estrictamente religioso, en este documento de corte humanista, la Iglesia Católica hace reflexiones políticas relacionadas con el racional

3 Caritas in Veritate es el principio sobre el que gira la Doctrina Social de la Iglesia, que adquiere forma operativa en criterios orientadores de la acción moral. Es importante recordar particularmente dos de ellos, requeridos en especial por el compromiso para el desarrollo en una sociedad en vías de globalización: la justicia y el bien común.

4 El Papa Pablo VI tenía una visión articulada del desarrollo. Con el término desarrollo quiso indicar, ante todo, el objetivo de que los pueblos salieran del hambre, la miseria, las enfermedades endémicas y el analfabetismo. Desde el punto de vista económico, eso significaba su participación activa y en condiciones de igualdad en el proceso económico internacional; desde el punto de vista social, su evolución hacia sociedades solidarias y con buen nivel de formación; desde el punto de vista político, la consolidación de regímenes democráticos capaces de asegurar libertad y paz. 
desempeño de la economía y propone una distribución solidaria y una economía al servicio del ser humano, y no al contrario, argumentos que de hecho descalifican la acumulación individual del capital como indicador del crecimiento y del desarrollo. Otros autores como Shultz consideran que el uso del tiempo libre es un indicador más apropiado del desarrollo que los clásicos parámetros asociados al PIB.

\section{Propietarios y medios de producción}

Marx y sus seguidores también contribuyen a estos debates. Para ellos, el conflicto básico en la sociedad se define por el enfrentamiento entre propietarios de los medios de producción y quienes solo poseen su fuerza de trabajo. De acuerdo con esta corriente, los mercados son productores de injusticia, mientras que para Rawls, en ellos prevalece la soberanía del consumidor. En nuestros tiempos, esa soberanía no es voluntaria, pues está constreñida por la influencia casi violenta de los medios de comunicación, que se convirtieron en agentes del capital con fines de aculturación, para transformar a los ciudadanos del mundo en esclavos del consumismo.

Con la profundización de la economía de mercado, en desarrollo del aperturismo de la década de los noventa, se produjo un debilitamiento de las instituciones democráticas liderado por los Estados, así como una exacerbación entre estas y los mercados, liderada por empresas trasnacionales, beneficiarias de los procesos de desregulación. En la agudización de la crisis del capitalismo de la última década, se ha afirmado que las empresas financieras en Wall Street tuvieron grandes ganancias, producto más de las buenas relaciones con el poder que de innovaciones en el sector. Podría afirmarse que fueron rentistas de la desregulación quienes manejaron la situación con conductas rayanas en el delito, sin tener juzgamiento apropiado, en nombre de la libertad de mercados. Al contrario, la intervención del Estado mediante operaciones de salvamento financiero ha dejado al descubierto su proceso de privatización, hecho que facilita que el gran poder económico sea el beneficiario de las instituciones estatales, en contravía del concepto histórico del Estado, que debería estar al servicio de la población. El sistema financiero internacional aplica con eficiencia la máxima de privatizar las ganancias y socializar las pérdidas.

Con el análisis de la crisis de 2007-2008 también aparecieron nuevas formas de defensa de la justicia distributiva, debido a la conducta especulativa que dominó el sector financiero asociado con el sector energético. Sin embargo, autores como Cohen relacionan las teorías de Rawls con la propuesta de aceptar niveles de desigualdad (Cohen, 2000, p. 124, en Boron, 2000a), pero no cuestionan las relaciones de explotación salarial que pueden tender a manejos esclavistas como ocurre en algunos países de América Latina con la intermediación laboral, particularmente en las conocidas empresas maquiladoras. La crisis de hoy tiene relación con fenómenos no solo económicos sino ecológicos, que de no considerarse con la seriedad que ameritan, pueden dar al traste con los esfuerzos de siglos para conservar la especie humana. El cambio climático o el agujero de la capa de ozono son fenómenos fehacientes de que la ecología ocupa uno de los primeros lugares en el interés por la resolución de problemas globales, causados en gran medida por la explotación exagerada de recursos y el consumismo desbordado como ícono del desarrollo.

En estas condiciones, si la desigualdad hace abstracción del fenómeno de la explotación, es muy difícil explicar la equidad en términos de distribución. En especial por el proceso acelerado de deslaboralización del trabajo, aplicado con las reformas laborales adelantadas en nombre 
de la denominada flexibilización laboral en los países, y las profundas injusticias en el trato de las migraciones que rayan en la criminalización entre Estados, a pesar de considerar esta movilidad humana como un signo de la sacralizada globalización. Esta sofisticación en el manejo de las relaciones laborales impide aplicar con claridad el principio de la justicia, en particular cuando los niveles de desempleo son elevados.

\section{Verdad y justicia en economía}

Ante el desconocimiento de las relaciones de explotación, la búsqueda de una sociedad justa se hace más difícil de establecer y de pactar. La solución de esta inequidad debería comenzar por reconocer que, históricamente, las condiciones laborales se desmejoran cada vez más, en contra de las aspiraciones de los trabajadores que anhelan salir de la pobreza extrema o relativa. Otro tipo de prácticas económicas se hacen necesarias si lo que se quiere es la verdad y la justicia. La economía social, asociada con economía solidaria, se refiere al conjunto de organizaciones de productores, consumidores, ahorradores, trabajadores y otros, que operan regidos por los principios de participación democrática en las decisiones, autonomía de la gestión y la primacía del ser humano sobre el capital. Las prácticas de estas organizaciones se circunscriben en una nueva racionalidad productiva, donde la solidaridad es el soporte del funcionamiento de las iniciativas, diferenciándose de la racionalidad capitalista, que no es ni solidaria ni inclusiva y de la economía pública, que limita la posibilidad de autogestión ${ }^{5}$.

5 Radrigán R. y Barria (2005) exponen el concepto de economía social desde un punto de vista contemporáneo y de procesos sociales, extendido y popularizado desde mediados de la década de los setenta, principalmente en América Latina, en donde se vivían los rigores de la crisis económica del petróleo. A esto se sumaba la profundización de un modelo económico neoliberal y la recesión internacional de inicios de la década de los ochenta. A la vez, desde una perspectiva política, en esta época, en la región
Podría afirmarse que autores como Rawls, que aceptan niveles de solidaridad, buscan humanizar el capitalismo sin cuestionar la fuente de la concentración de la riqueza para que la explotación tenga niveles aceptables y sostenibles en el proceso de reproducción de este sistema dominante. Otro es el sentido de la solidaridad en Tomás de Aquino, que incorpora la idea de compartir, más que el término de distribución que se consolida con el método Lebret de la economía incluyente. Para Benedicto XVI, las normas de justicia deben ser respetadas desde el principio y durante el proceso económico y no solo después y de manera colateral (Caritas in Veritate, 2000, p. 54). En este contexto, la verdad es la base de la Doctrina Social de la Iglesia y de las macrorrelaciones sociales, económicas y políticas. La verdad crea diálogos. Sin verdad no hay responsabilidad social. Por estas razones, la fidelidad a la verdad es la auténtica fuente de la libertad (C. in V., 2009).

El compromiso para el desarrollo incluyente debe fundarse en la justicia y en el bien común. Cuando el objetivo último es el beneficio sin incorporar el bien común como orientador, se corre el riesgo de destruir riqueza e incrementar la pobreza. Para construir el derecho primario a la vida es necesario el cumplimiento de dos derechos mínimos vitales: los derechos a la alimentación y al agua.

El binomio mercado-Estado corroe la sociabilidad, mientras que las formas de economía solidaria crean sociabilidad y pueden ser fuente de cohesión social en razón a la pluralidad de formas institucionales de empresa, a la vez que promueve un mercado más cívico (C. in V., 2009, p. $54)$. 


\section{Economía solidaria}

La economía solidaria no solo incorpora los elementos básicos de la teoría económica de los economistas clásicos, neoclásicos, keynesianos y sus expresiones actuales, así como el denominado institucionalismo, sino todas las corrientes de pensamiento con énfasis en la pluralidad de la economía social, por su pertinencia en términos de la democracia económica que es fuente de la democracia política. La redistribución, que puede ser base de la economía solidaria, no debe ser lo único para combatir la desigualdad; es necesario apoyarse en políticas públicas activas que aseguren los derechos sociales de la comunidad. El estudio de la pobreza, de la desigualdad, de la exclusión social debe complementarse con análisis de la formación de la riqueza legítima e ilegítima para construir sociedades con niveles ciertos de cohesión social.

La economía social debe entenderse como la conjunción de tres tipos de intereses que pueden ser la fuente de la cohesión social y del crecimiento y desarrollo sostenibles. El interés mutuo, que hace referencia a organizaciones empresariales de carácter cooperativo, en las que se incluyen fondos de empleados, mutuales y organizaciones similares a las mypimes, reconocidas por ser grandes generadoras de empleo; el interés general, que incorpora las ONG que se ocupan de derechos humanos y seguridad humana, y el interés público, asociado con los derechos de acceso a educación, salud, vivienda y servicios públicos, en donde el gasto público social es vital para su pleno cumplimiento.

\section{Desarrollo y seguridad humana}

El desarrollo es la condición de vida de una sociedad en la que las necesidades auténticas de los grupos e individuos se satisfacen mediante la utilización racional y sostenida de los recursos y los sistemas naturales, que, al ser reservas de valor, deben estar al servicio de toda la población. En este proceso se emplean tecnologías que no riñen con los elementos culturales de los grupos involucrados. Este concepto integra elementos económicos, tecnológicos, de conservación y utilización ecológica, así como componentes sociales y políticos. El círculo de poder se destaca como forma organizativa y de cohesión legítima, legal y funcional dentro de grupos sociales y como instancia trascendente en la toma de decisiones. Un corolario de fácil aplicación en la definición de desarrollo establece que este está caracterizado por condiciones en las que los bienes y servicios deben estar al alcance de los diferentes grupos que conforman la sociedad, con el fin de solucionar sus necesidades vitales y socioculturales.

Una de las principales advertencias de los conceptos de la Organización de las Naciones Unidas (ONU) es la reafirmación de que las medidas macroeconómicas centradas en aspectos de producción y su relación con las poblaciones, como el ingreso per cápita o el PIB nacional, tienen limitaciones. Entre ellas se encuentra la evidencia de que si bien es cierto que el desarrollo implica posesión y dominio económico hasta determinado nivel, no se reduce solo a la generación de riqueza. Se resalta la importancia en el desarrollo humano, que incluye dos facetas complementarias. La primera de ellas es la formación de las capacidades humanas; la segunda, que esas capacidades puedan ser ejercidas en las diferentes esferas de la vida: económica, social, cultural o política.

La seguridad humana se basa en el entendimiento fundamental de que los gobiernos tienen la función primordial de asegurar la supervivencia, los medios de vida y la dignidad de sus ciudadanos. Es un instrumento inestimable para ayudar a los gobiernos a determinar amenazas graves y generalizadas al bienestar de su población y la estabilidad de su soberanía; promueve programas y políticas 
para hacer frente a nuevas amenazas y responde a ellas en forma pertinente y priorizada. Lo anterior secunda a los gobiernos y a la comunidad internacional en la mejor utilización de sus recursos y elaboración de estrategias que fortalezcan el marco de protección y empoderamiento para la seguridad humana y la promoción de la paz y la estabilidad en todos los niveles: local, nacional, regional e internacional (Cadena, 2011).

La Cumbre Mundial de 2005 y la decisión de la Asamblea General de las Naciones Unidas de definir en mayor detalle el concepto de seguridad humana han sido fundamentales para divulgarlo y despertar el interés general. En el párrafo 143 del documento final de dicha Cumbre, los jefes de Estado y de gobierno reconocieron que "todas las personas, en particular las que son vulnerables, tienen derecho a vivir libres del temor y la miseria, a disponer de iguales oportunidades para disfrutar de todos sus derechos y a desarrollar plenamente su potencial humano". En virtud de ese reconocimiento, los Estados miembros de las Naciones Unidas aceptaron examinar a fondo el concepto de seguridad humana. Con los aportes de varios gobiernos, de organizaciones intergubernamentales, grupos de la sociedad civil, académicos y algunos expertos, este instrumento está adquiriendo amplio apoyo en la ONU y otros foros.

La seguridad humana debe entenderse, según la ONU, como una condición o situación que supone un cambio de perspectiva u orientación, en la que se valore al mundo tomando como núcleo de referencia a las personas, más allá de consideraciones concernientes a la seguridad estatal. Se trata de una idea-fuerza multiforme, aplicable en diversos contextos sociales, que asocia e incluye diferentes condiciones para el pleno desarrollo humano (Pereira, 2011).
De acuerdo con este novedoso concepto interdisciplinario, la seguridad se fundamenta primordialmente en la promoción y protección de los derechos de la ciudadanía, que garantizan el bienestar y la satisfacción de las personas en el marco de la propia sociedad, más que en el esquema convencional de fortalecimiento del Estado y la defensa armada de sus instituciones ante posibles amenazas, intimidaciones o asechanzas internas o externas.

En efecto, quienes hoy impulsan acciones relacionadas con la seguridad humana dispensan prioridad a la seguridad de los individuos y las comunidades, sobre todo a la lucha contra el hambre, la pobreza, epidemias, desastres naturales, violencia y situaciones similares. Por eso, la seguridad humana implica proporcionar a las personas protección contra amenazas u obstáculos violentos y no violentos. Obviamente, el concepto es muy amplio, complejo y general, debido a que ha sido abordado desde diferentes perspectivas por las instituciones internacionales y nacionales y los gobiernos.

Se puede asegurar que la seguridad humana conlleva a un cambio drástico entre el enfoque tradicional de seguridad que implica una reforma compleja y dramática en la conceptualización de seguridad desde un nuevo modelo analítico y político de corte multidimensional y con numerosas visiones de la realidad internacional ${ }^{6}$.

El Tercer Mundo y los países desarrollados en crisis son los beneficiarios directos de esta concepción del desarrollo.

\section{8. Áreas básicas de la seguridad humana}

Para una mejor comprensión y aproximación a su logro, la seguridad humana suele desglosarse en varias áreas

6 Para profundizar, véase Ortiz (2003, pp. 43-60). 
básicas de pertinencia y compromiso que, por supuesto, están fuertemente interrelacionadas (ONU, 2002). Estas incluyen seguridad ambiental, seguridad científica y tecnológica, seguridad cultural, seguridad económica y financiera, seguridad en función de igualdad de género, seguridad jurídica y seguridad social. Se han reconocido ciertas condiciones mínimas, cuya vigencia resulta indispensable para encaminarse al logro de la seguridad humana.

En el ámbito de la libertad de acceso a los beneficios derivados del desarrollo científico es necesario entender la transferencia de tecnología (Martínez, 2004) como un mecanismo estratégico para el desarrollo mundial incluyente y como un mecanismo de compensación por los prolongados procesos de expoliación de los recursos naturales de los países aportantes de las materias primas necesarias para el desarrollo mundial, en especial las asociadas con recursos naturales estratégicos relacionados con la energía.

\section{Conclusiones}

Tras considerar que la economía social se orienta a la solución de problemas mediante la correcta distribución de los recursos y después de controvertir las teorías tradicionales por cuanto no han llenado las expectativas de los grupos humanos menos favorecidos, las crisis del nuevo siglo exigen respuestas apropiadas y posibles de cumplir por parte de la sociedad en general, pero en especial por quienes desde la academia tienen la responsabilidad de formar y educar a la juventud que en los próximos años tendrá que acudir al relevo generacional para regir los destinos de sus países.

El discurso filosófico sobre el capital y su incidencia en la vida del hombre ha sido superado, por ahora, por nuevas tendencias y teorías que, apoyadas en conceptos de la política, como democracia y libertad, se abren paso en el mundo globalizado y han generado cada vez mayor desigualdad en la distribución de la riqueza. La proporción de apropiación privada de la riqueza suscitada por el alto crecimiento de los precios de las materias primas en la economía mundial no se corresponde con la disminución de la pobreza y menos con el grado de desigualdad en la distribución de la riqueza que se mantiene en la mayoría de los países, especialmente de los denominados del Tercer Mundo. Hoy la economía se rige por los principios de eficiencia, eficacia y libre mercado contaminado por la ausencia de verdad y por la corrupción asociada.

Desde el punto de vista de la economía social, el libre mercado no ocurre cuando se refiere a la movilidad del trabajo, ni cuando se refiere a la transferencia de tecnología; ni tampoco es evidente cuando se trata del factor tierra, salvo cuando se producen las compras de territorios en diferentes países por parte de las trasnacionales que se ocupan del mercado de futuros relacionados con producción de alimentos o de biocombustibles. En cambio, la libertad de mercado ocurre cuando se trata de la movilidad libre del capital que no aporta tributos en los países por donde hace su recorrido en búsqueda de reproducción. Por su parte, la acumulación de capital ha coadyuvado al mejoramiento de las condiciones de vida de las comunidades más pobres con niveles mínimos de disminución de la pobreza en medio de un incremento significativo de la violencia. A lo anterior se suma un marcado proceso de macromilitarización de la economía internacional y paramilitarización de las economías nacionales, así como la pérdida de los valores nacionales. Estos hechos generan reacciones que comprometen a instituciones que bien pudieran estar trabajando en actividades inherentes al desarrollo nacional en búsqueda del bien común.

El único poder capaz de incorporar a todos los demás es el económico. En tal virtud, todos los conceptos humanistas se encuentran congelados por no adaptarse a las conveniencias del sistema imperante cuyo fin principal 
es la acumulación privada, alejada de la solidaridad. Las actuales amenazas en la sociedad del riesgo imponen un nuevo tipo de economía orientada tanto a satisfacer las necesidades mínimas como a masificar los principios de solidaridad y cooperación en el ámbito de los derechos.

La aparición de nuevos grupos de poder con intenciones políticas de refundación del Estado y de ascenso social, mediante la ostentación y aplicación de la violencia, ha generado reacciones a nivel internacional, con el fin de proteger a la sociedad e impedir la pérdida total de valores que afectan, incluso, las bases de los nacionalismos. A tales extremos ha llegado el interés de algunos grupos por acumular a toda costa, que varias trasnacionales han secuestrado literalmente el derecho en varios países proclives al liberalismo económico extremo, incluso con la legitimación mediante ardides inconstitucionales de dineros provenientes del crimen organizado. Hoy es posible hablar de la guerra contra el tráfico de drogas y de la influencia geopolítica de este fenómeno. Lo más grave es que los recursos económicos procedentes del crimen han servido para comprar el poder y para corromper las instituciones que antaño fueron la base fundacional del Estado-nación.

El Estado, como institución de derecho, debe desplegar su atribución de organizar a las demás instituciones, asegurando el acceso de los ciudadanos a sus derechos. Pero el poder, cuando se transforma en fuerza irracional y desvía su naturaleza originaria a una sociedad de libre mercado y libre comercio, puede facilitar la existencia del mercado como orientador de la economía, apelando a acciones dictatoriales para limitar las expresiones sociales de regulación y control político del capital. En este sentido, un manejo convergente entre economía pública, economía privada y economía social puede facilitar el crecimiento económico con justicia social en el ámbito de la economía sostenible con cohesión social.

\section{Referencias}

Barry, B. (1993/1973). La teoría liberal de la justicia. México: Fondo de Gultura Económica.

Benedicto XVI (2009). Caritas in Veritate. Carta Encíclica del Sumo Pontífice sobre el desarrollo humano integral en la caridad y en la verdad.

Bentham, J. (1991). Deontology or the Science of Morality. Josep María Colomer. (Ed.). Barcelona: Península.

Blaug, M. (1996). Economic theory in retrospect. Cambridge: Cambridge University Press.

Boron, A. A. (1999a). La filosofía política clásica y la biblioteca de Borges. En Atilio A. Boron (comp.). La filosofia política clásica. De la Antigüedad al Renacimiento. Buenos Aires: Clacso/Eudeba.

Boron, A. A. (1999b). Introducción. El marxismo y la filosofía política. En Atilio A. Boron (comp.). Teoría y filosofia política. La tradición clásica y las nuevas fronteras. Buenos Aires: Clacso/Eudeba.

Boron, A. A. (2000a). Lectura sin capitalismo, capitalismo sin frustración, una reflexión de las teorías de Fohn Rawls. Ponencia postulada a la Primera Jornada UBA/USP de Teoría Política, Brasil, 14-15 de septiembre.

Boron, A. A. (2000b). Filosofía política y crítica de la sociedad burguesa: el legado teórico de Karl Marx. En Atilio A. Boron (comp.). La filosofia política moderna. De Hobbes a Marx. Buenos Aires: Clacso/Eudeba.

Brink, D. (1989). Moral Realism and the Foundations of Ethics. Cambridge: Cambridge University Press. 
Cadena M., J. L. (2011). Geopolítica del agua en Colombia: la seguridad humana frente a los intereses transnacionales. Revista CIFE, 13(19), 127-150.

Cárdenas Rivera, M. E., y Cháves Díaz, F. (2011). La economía social: concepto y reinterpretación. Revista CIFE, 18(13), 13-38.

Cháves, J. A. (2002). Ética y economía: La perspectiva de Amartya Sen. Estudios Filosóficos 51(146), 5-37.

Cohen, G. A. (1991). If you're an Egalitarian, How come you're so Rich? Cambridge: Harvard University Press.

Cohen, M., Nagel, T. \& Scanlon, T. (comps.) (1980). Marx, Fustice and History. A. Philosophy \& Public Affairs Reader. Princeton: Princeton University Press.

De Vita, Á. (2000). A justiça igualitária e seus críticos. São Paulo: Editora Unesp.

Engels, F. (1966/1875). Carta a August Bebel, 18 de marzo de 1875, incluida en Karl Marx, Crítica del Programa de Gotha. Recopilada en Karl Marx y Friedrich Engels. Obras Escogidas. 2 ts. Moscú: Editorial Progreso.

Fernández Pereira, J. P. (2005). Seguridad humana.Tesis doctoral, Universidad Autónoma de Barcelona. Recuperado de http://www.tdr.cesca.es/tesis_uab/ available/tdx-0620106-153920/jcfpldel.pdf consultado el 02 de junio de 2012 a las 12 p.m.

Fukuyma, F. (1992). El fin de la historia y el último hombre. Barcelona: Editorial Planeta.

Gargarella, R. (1999). Las teorías de la justicia después de Rawls. Un breve manual de la filosofia política. Barcelona: Paidós.
Hayek, F. A. (1978). Lare, Legislation and Liberty, vol. 2: The Mirage of Social Justice. Chicago and London: The University of Chicago Press.

Japiassu, H. (2000). Nemtudoé relativo. A quetão da verdade. São Paulo: Letras y Letras.

Lebret, L. J.. El institucionalismo americano: Origen y presente. Revista de Economía Institucional 9(16), 315-325.

Lorino, P. (1993). El control de gestión estratégico. Barcelona: Editorial Marcombo.

Martínez, G. J. (2004) (Ed.). Integración regional, fronteras y globalización. Bogotá: Universidad Nacional de Colombia.

Mourão, P. R. (2008). Hechos y valores en el pensamiento económico: una reflexión epistemológica. Revista de Economía Institucional, 10(18), 381-394.

Organización de la Naciones Unidas - ONU (2002). Departamento de Información Pública. Preparado en español por la Sección del Sitio Internet de la División de Noticias y Medios.

Ortiz Navarrete, J. (2003). La doctrina de la seguridad humana en la política exterior canadiense. La contribución de Lloyd Axworthy al estudio de la política mundial. Revista Cidofbd'afers Internacionals, 60, 43-60.

Pinto, P. (2000). A Word on Economic Method. Symposium Proceedings "Economics and Public Policy", Sidney.

Przeworski, A. (1989). Capitalismo y social democracia. Madrid: Alianza Editorial. 
Radrigán Rubio, M., Barria K., C. (2005). Situación y proyecciones de la economía social en Chile. En José María Pérez de Uralde (coord.). La economía social en Iberoamérica: un acercamiento a su realidad. Madrid: Fundibes.

Rawls, J. (1971). A Theory of Justice. Cambridge: Harvard University Press. [Versión en español: (1979). Teoría de la fusticia. México: Fondo de Cultura Económica].

Rawls, J. (1985). Justice as Fairness: Political not Metgaphysical. Philosophy and PublicAffairs, 14(3),
223-25 1 [Versión en español: (1996). La Política. Revista de estudios sobre el Estado y la sociedad I (1), 23-46].

Sayre-McCord, G. (1988). Essays on Moral Realism. New York: Cornell University Press.

Sen, A. (1980). Description as Choice. Oxford Economic Papers, 32(3), 353-369.

Wittman, D. (1995). The Myth of Democratic Failure: Why Political Institutions are Efficient. Chicago: The University of Chicago Press. 